This is the final peer-reviewed accepted manuscript of:

Renata Galatolo, Biagio Ursi, Ramona Bongelli, Parasitic Apologies, «Discourse Processes», 2016, 53:12, pp. 97-113

The final published version is available online at:

https://doi.org/10.1080/0163853X.2015.1056694

Rights / License:

The terms and conditions for the reuse of this version of the manuscript are specified in the publishing policy. For all terms of use and more information see the publisher's website.

This item was downloaded from IRIS Università di Bologna (https://cris.unibo.it/)

When citing, please refer to the published version. 


\title{
Parasitic Apologies
}

\author{
Renata Galatolo \\ Department of Philosophy and Communication \\ University of Bologna, Bologna, Italy \\ Biagio Ursi \\ ICAR Research Lab \\ University of Lyon, Lyon, France
}

Ramona Bongelli

Department of Political Sciences, Communication and International Relations

University of Macerata, Macerata, Italy

\begin{abstract}
The action of apologizing can be accomplished as the main business of the interaction or incidentally while participants are doing something else. We refer to these apologies as "parasitic apologies", because they are produced en passant (Schegloff, 2007), and focus our analysis on this type of apology occurring at the opening of the call. Such apologies are autonomously produced by the caller or by the call receiver, displaying the urgency to repair potential contact troubles, and find shelter inside the opening of the call, at the expense of some phases that routinely occur. The results of our analysis show interesting associations between the apologizer (the caller or the call receiver), the structure of the parasitic apology, and the impact it has on the structure of the opening sequence.
\end{abstract}

\section{INTRODUCTION}

A distinct group of apologies was observed in the collection described in the editors' introduction that occur at the opening of the call or at the moment of the

Correspondence concerning this article should be addressed to Renata Galatolo, Department of Philosophy and Communication, University of Bologna, Via Azzo Gardino, 23 - 40122 Bologna, Italy. E-mail: renata.galatolo@unibo.it 
contact between the two parties, including cases where the telephone was answered by someone other than the intended recipient. We refer to these as "parasitic apologies" because they are produced en passant (Schegloff, 2007) during the call opening, to which participants, despite the apology's production, show to orient as the main activity in which they are involved. Coming as they do in call openings, including the initial exchange between the caller and their intended recipient, such apologies manifest callers' undertakings to repair such matters as delays in having contacted the recipient or, more generally, in getting in touch, having made the interlocutor wait on the phone or disturbing the interlocutor by calling at what might be an inconvenient time-in other words, repairing "contact troubles." These apologies find shelter inside the opening of the call, at the expense of some phases that routinely occur, and their production may entail the momentary suspension of some of those phases or even their suppression and moving on.

We explore cases such as this:

(1) The Telephone book [Schegloff - 80b, 122]

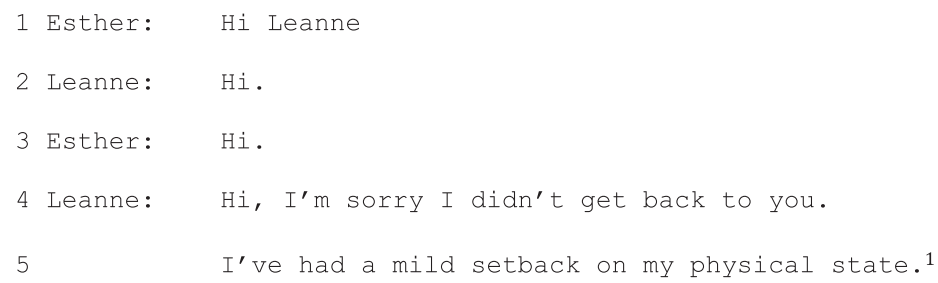

The apology in line 4 is produced at the first available conversational slot, immediately after the expected "Hi" reciprocation, in a certain way exploiting the conversational opportunities provided by the opening sequence.

In our corpus, all apologies are autonomously provided by the apologizer and not explicitly solicited by a previous turn. They don't occur in response to a complaint or to the mention of a problematic matter, and they can even be triggered by the simple fact of getting in touch. Their occurrence at the very beginning of the call and not in response to previous turns explains why in all the examples we selected the apologizable comes packaged with the apology (Schegloff, 2005) that introduces it. All parasitic apologies are thus composed of the [apology component] + the [apologizable], that Heritage and Raymond (this issue) define as expanded apologies. ${ }^{2}$ The third component, the account, is present only in one of the two types of parasitic apologies we identified, that is,

\footnotetext{
${ }^{1}$ Schegloff analyzes this example dealing with complainability and focuses on the manners it can emerge and it can be addressed in interaction (Schegloff, 2005, p. 462).

${ }^{2}$ For a definition of the components of apologetic turns, see Drew \& Hepburn and Heritage \& Raymond, this issue.
} 
those produced by the called person and entailing the momentarily suspension of the opening of the call.

In all examples both the apologizer and the apologizee contribute to constructing the parasitic character of the apology. On one hand, the apologizer produces the apology at the first available conversational slot (depending on who - the caller or the called party-apologizes) while something else is going on; on the other hand, the apologizee may produce mere acknowledgements, unelaborated absolutions, or no reply at all. Notably, the instances of our corpus are examples of rather compressed apology sequences (except two cases in which narrative accounts follow the apology), as far as the apologizable doesn't emerge before the apology, in terms of more or less explicit complainable matters, and even the responses tend to be rather unelaborated.

In all our cases parasitic apologies display a special relationship with urgency and, in general, with the connection between speed and relevance of social actions' accomplishment. This issue, and the related issue of who is the apologizer - the caller or the call receiver-is the focus of the next section.

\section{ANALYSIS}

These parasitic apologies are realized as en passant activities but differ regarding the apologizer, the impact they have on the overall organization of the call opening sequence, and the function they accomplish. Indeed, parasitic apologies that are produced by the called party may cause the provisional suspension of the opening phase, which is then resumed. Alternatively, the caller can create the conditions for the compression of that same phase and the immediate passing over. In doing so the formulation of the reason for the call is intertwined with the construction of the apology and projected by the parasitic positioning of the apologetic turn.

We show below the standard call opening sequence, on which parasitic apologies impact, causing its alteration:

$\begin{array}{lcc}\text { (2) [From Schegloff 1986: 115; Drew \& Chilton 2000: 140-141] } & \text { ring } \\ 0 \text { (i) Summons } & \text { R } & \text { Hallo, } \\ 1 & \text { Answer } & \text { Hello Jim? } \\ 2 \text { (ii) Identification/ } & \text { C } & \\ 3 & \text { Recognition } & \text { Yeah, } \\ 4 & \text { C } & \text { 'S Bonnie. }\end{array}$




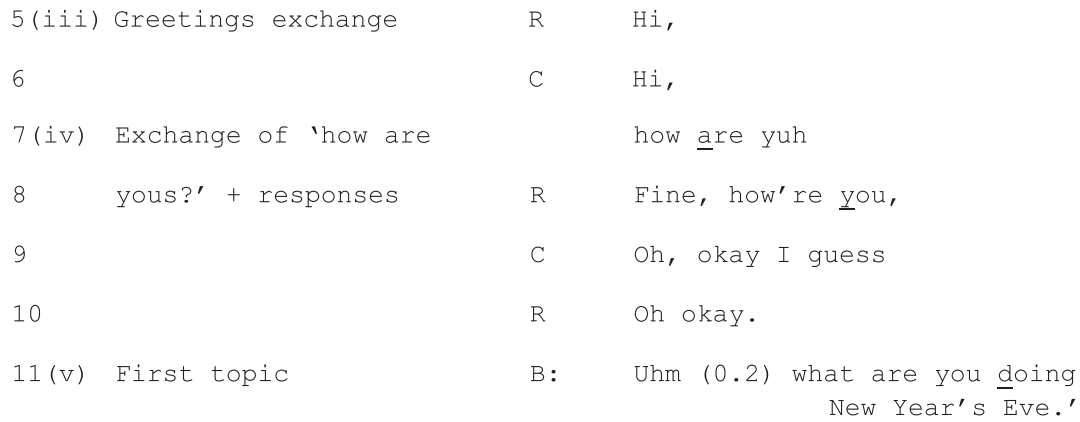

6

7 (iv) Exchange of 'how are

As shown in (2), Schegloff (1986) identifies four components of the call opening sequence: the summons/answer component (i.e., the phone ring followed by a vocal response by the recipient, confirming the openness of a channel of communication); the identification of the interlocutor, which is a mutual task, potentially accomplished via recognition; the greetings, which are generally ritualized and can be accomplished by one party or both; and the "how are you" sequence, that is, the exchange of initial inquiries. The next phase is the introduction of the reason for the call, which corresponds to the caller introduction of the first topic.

\section{Suspending the Opening Sequence}

The insertion of the apology in the opening sequence can have the effect of momentarily suspending the opening of the call, as in the following example:

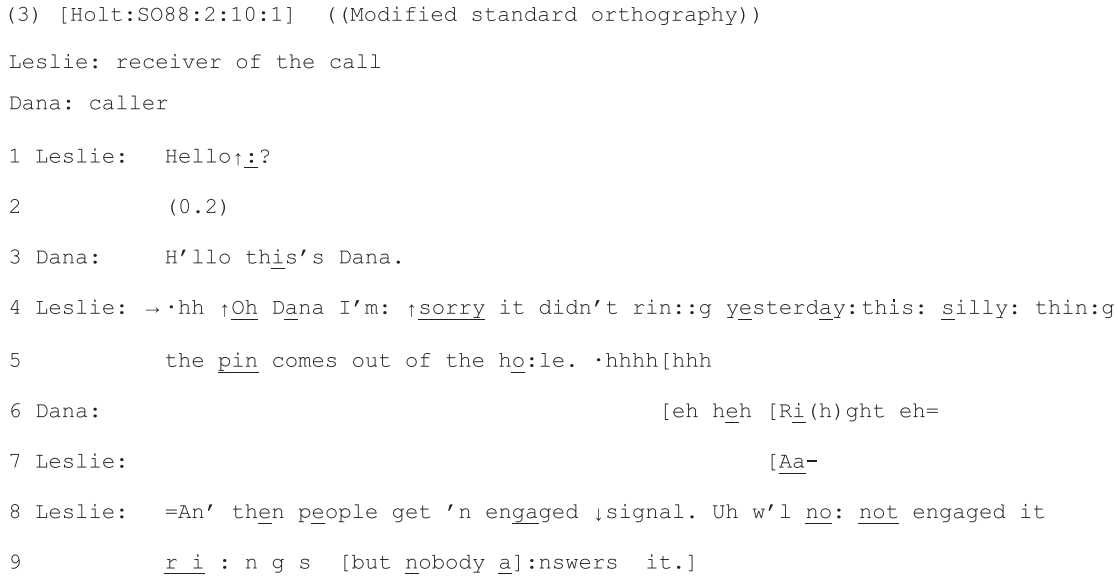




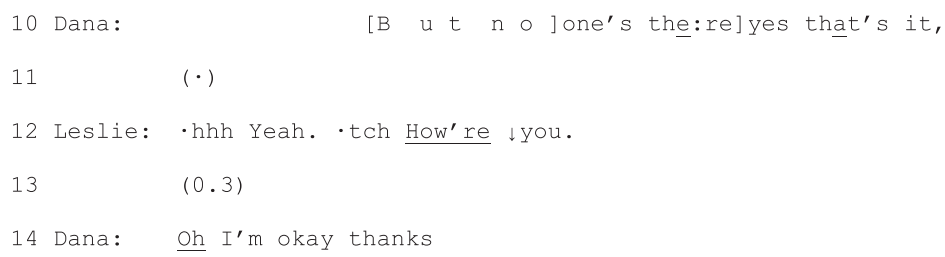

In this example, ${ }^{3}$ the apology at line 4 is produced immediately after the identification/recognition sequence, where the "how are you" sequence canonically occurs (Schegloff, 1986). After Dana's self-identification (line 3), Leslie produces a brief in-breath followed by the "Oh" change-of-state token (Heritage, 1984) associated with the caller name, Dana. Though the "Oh Dana" displays Leslie's recognition of her interlocutor, the subsequent "I'm: $\uparrow$ sorry" retrospectively enriches Leslie's initial change of mind with the sense of an immediate orientation to a problematic matter, which she treats through the apology and then clarifies through the mention of the apologizable ("it didn't ring:: yesterday:" at line 4, referring to a trouble with the phone device) followed by a detailed account ("the pin comes out of the ho:le $[\ldots]=$ An' then people get 'n engaged signal. Uh w'l no: not engaged it ri:ngs but nobody a:nswers it.", lines $5,8,9$ ).

The apologizable comes packaged with the apology that introduces it. Indeed, the turn preceding the apology doesn't contain any direct or indirect complaint, and it is the simple fact of having Dana on the phone that determines Leslie's orientation toward a previous lack of contact as a complainable matter, which makes her immediate remedial action relevant. The apologizer (Leslie) spontaneously addresses the potential complainability of something previously occurred, in a certain way preventing the complaint to surface (Schegloff, 2005). ${ }^{4}$

The apology location after the second component of the identification/ recognition sequence ("Oh Dana", at line 4), in place of the expected greetings or "how are you" sequence, which is in fact resumed at line 12, creates an effect of urgency in the apology's production. The called person (Leslie) mobilizes a past event (i.e., a missing contact) as a preliminary concern for the phone call, even before the reason for the call is actually communicated. In this case the apologizable, that is, the day before lack of contact, is even not overtly mentioned but just evoked through the mention of the device malfunction ("it didn't ring") and the following narrative in which Leslie provides further details (lines 5, 8, 9).

\footnotetext{
${ }^{3}$ For a detailed description of the context of this call, see Heritage \& Raymond, this issue.

${ }^{4}$ Schegloff calls this phenomenon complaint pre-emption: "[...] parties to an interaction can understand some ostensibly innocent talk, especially questions, as possibly pre-figuring a recognizable course of action, and can respond in a fashion designed to interdict the move to engage in that course of action. [...] Complainability, then, is recognizable (by other than the potential complainer) in advance of a complaint, and can result in the non-surfacing of the complaint itself"' (Schegloff, 2005, p. 452).
} 
Here, the apology is produced to be perceived as an intruder into a sequence that would have "normally" developed in a different direction (probably a reciprocal "how are you" exchange). The apology and the subsequent account momentarily suspend the main activity of opening the call in which the two women are engaged and that Leslie resumes with the "how are you" at line 12. The fact of resuming the opening of the call at the point where it had been left makes the apology and the subsequent account parasitic with regard to the main activity of opening the call, as they take advantage of the conversational space usually dedicated to other conversational activities. The parasitic character of the apology is reinforced by the fact that Dana's "right", 5 at line 6, is an ambiguous reply to the apology under several respects: it occurs rather late after the sorry component and is produced while laughing, so that it maintains its ambiguity between responding to the apology and aligning with Leslie's colorful storytelling. Leslie's overlapping on the "right" with the continuation of her storytelling (the "Aa" at line 7, then repaired at line 8) also provides evidence that she is not at all oriented to Leslie's acceptance of the apology as relevant. At line 10 Dana displays her understanding of Leslie's account and aligns with Leslie's complaint about the phone device. Dana's alignment and understanding are reinforced by the coproduction of the last part of Leslie's turn ("but nobody answers it," line 9) and the subsequent "that's it" (line 10) signals her orientation to the conclusion of the current activity. At line 12 Leslie briefly aligns with Dana's closing proposal through the acknowledgment ("Yeah") and immediately produces the first component of the "how are you" sequence. Therefore, both interlocutors orient to the apology and to the following account as a parenthetical activity that occurs within the main ongoing activity of opening the call.

In excerpt 4 below, a similar phenomenon occurs when Leslie comes to the phone after another member of Leslie's family answered the phone while she was occupied in the kitchen.

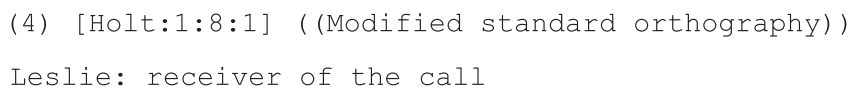

${ }^{5}$ For an analysis of preferred responses to apologies, among which the form "that's right," see Robinson 2004, p. 302. 


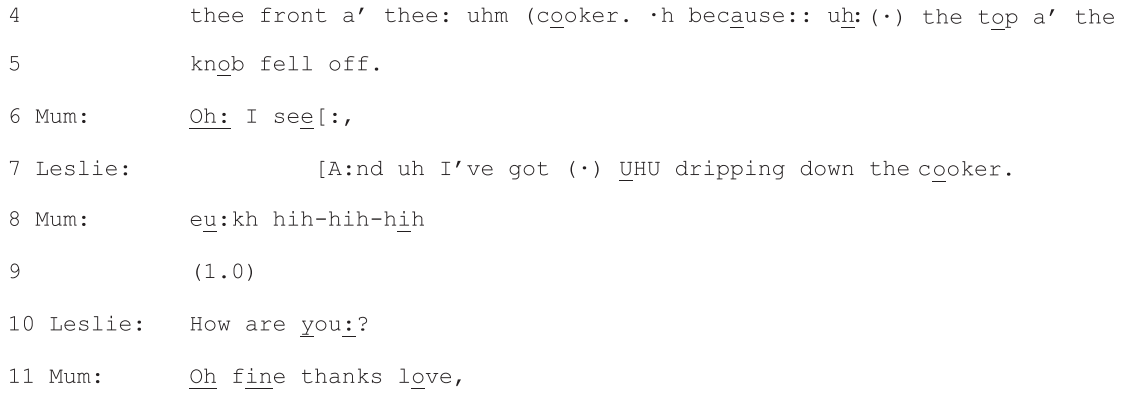

In this excerpt the opening phase is extremely compressed in the reciprocal "Hello" and immediately followed by Leslie's apology at line 3, "I'm sorry tuh keep you". 6 The apology replaces the unmarked development of the opening sequence, that is, the greetings or the "how are you" exchange, which is in fact resumed by Leslie at line 10 .

As in the previous example, no complaint or problematic matter emerges in the interaction before the apology is produced. It is the apology that, introducing the apologizable, retrospectively constructs Leslie's mother wait as a potential complainable. Unlike the previous example, however, in which the apologizable was a distal problem (Heritage \& Raymond, this issue), the missing contact the day before, in this case Leslie's apology addresses a local problem, the interlocutor's waiting on the phone. ${ }^{7}$ Indeed, Leslie's apology responds to the fact of having kept her mother waiting on the phone and treats the waiting as a potential complainable. This could explain the apology's position in the turn, that is, its occurring at the very beginning, immediately adjacent to its apologizable and the consequent sense of urgency.

Similarly to excerpt 3 , in excerpt 4 the apology is followed by a brief storytelling (lines 3-5), having the function of an account, that explains the reason of the offense. Leslie's mother replies to her daughter with a "mere acknowledgement" ("Oh: I see:", at line 6) that, following Robinson (2004), is a dispreferred answer to the apology because it doesn't address the act of apologizing, as the absolution does, or the problematic character of the apologizable, as in the case of its denial. Hence, Leslie's mother's reply, by

\footnotetext{
${ }^{6}$ The compression of the call opening in (4) can probably be explained also by the previous contact with a third person, who actually answered the phone, so that the recognition phase may result useless and redundant.

${ }^{7}$ On this point, see also Margutti, Pugliese, \& Traverso, this issue.
} 
avoiding an overt address to the apologetic components of the previous turn, remains ambiguous. ${ }^{8}$ At line 10 , after a pause of 1 second, Leslie resumes the opening sequence by the "how are you." In so doing she orients to the apology and the account as en passant activities that, occurring when something different would be expected, remain parasitic to the main one.

It is noteworthy that in both excerpts 3 and 4 the apologizable is a problematic aspect of getting in touch and the apology is produced by the receiver of the call who shows a kind of urgency by providing it at the very first occasion, that is, just after the interlocutor identification/recognition (excerpt 3) or immediately after the opening of the contact (excerpt 4). The effect of urgency is obtained through the apology's placement and through the delayed accomplishment of the call opening that it entails. ${ }^{9}$

In the following sections we show different courses of actions and responses occurring when the apology is produced by the caller, still at the opening of the call. The analysis will show the intertwining between the impact that the apology has on the opening sequence structure and the matter of who apologizes.

\section{Compressing and Passing Over the Opening Sequence}

In some cases the production of the apology can lead to the anticipation of the reason for the call, definitely suspending and compressing the opening stage. In these cases the apology creates the same effect of urgency we found in the previous excerpts, but unlike excerpts 3 and 4, there is no resuming of the activity of opening the call.

In our corpus we found two main formats that participants use to accomplish this task. The first one is composed of the apology plus the interlocutor's absolution, which is a more interlocutory format to introduce variations within the call opening structure; the second one is the caller's passing through the opening phase and introducing the reason for the call within the same turn. In this last case a rather unilateral alteration of the standard opening sequence is accomplished by the caller.

Compressing the opening sequence via embedded apologetic exchange. In these following two excerpts the participants collaboratively compress the standard opening sequence, on behalf of an early introduction of the reason for the call, through an apologetic exchange that includes the apology and

\footnotetext{
${ }^{8}$ This is in line with Robinson's results. The author states that unambiguously dispreferred responses are extremely rare in the data he analyzed (Robinson 2004, p. 315). See also Biassoni Diadori, Fatigante, \& Marazzini, this issue, for the analysis of this and other similar responses to the apologies.

${ }^{9}$ For a similar analysis of the role of accounts in call openings, see Drew \& Chilton (2000).
} 
the interlocutor's absolution. In this case the parasitic apology is configured as a distinct exchange embedded in the opening sequence, which is compressed.

In both excerpts 5 and 6 the parasitic apology pattern is composed of ["sorry to bothering you" $]+$ [absolution $]+$ [reason for the call]:

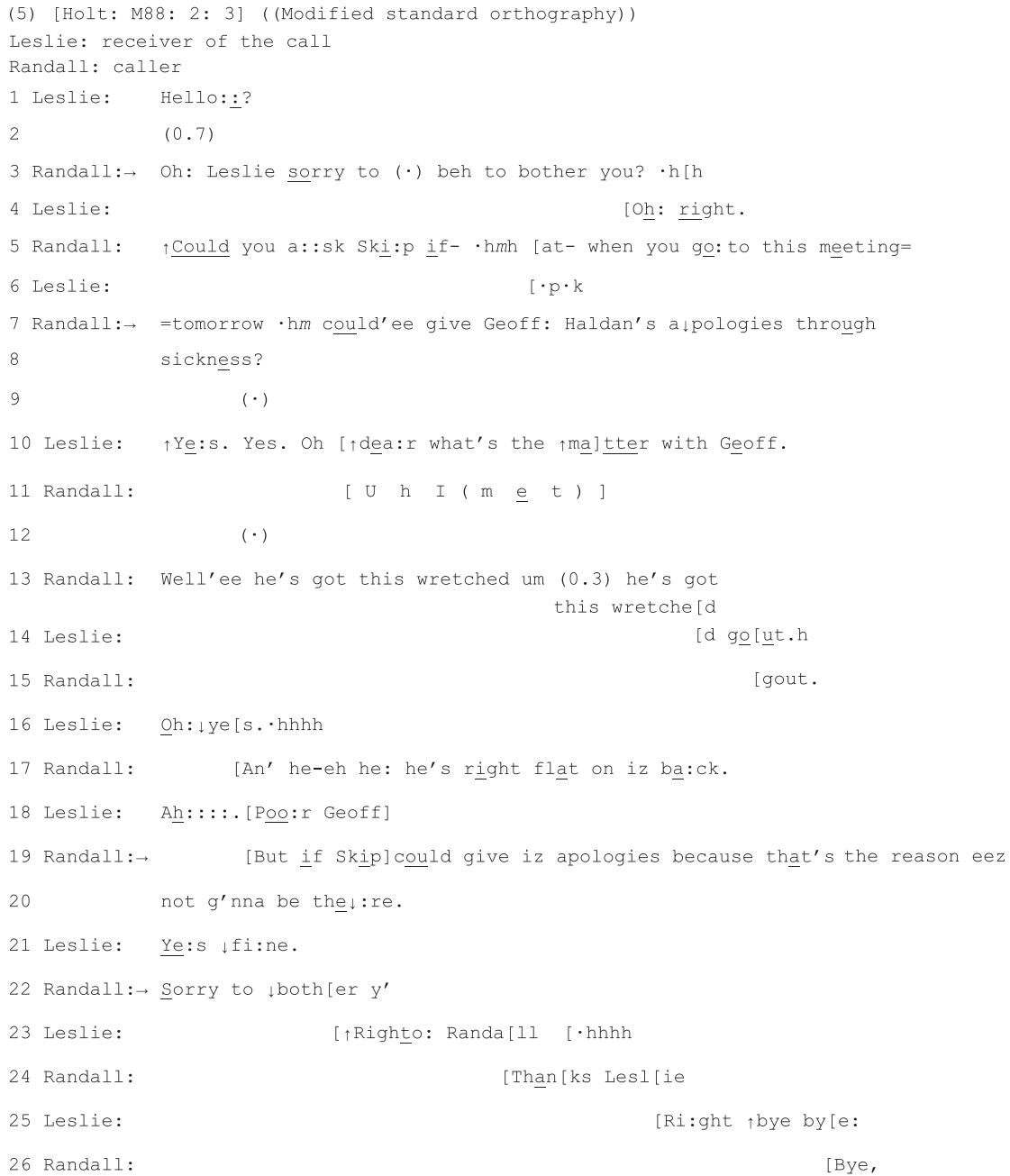

In the example above, the identification/recognition sequence is very compressed and the caller (Randall) immediately produces the apology in his first turn ("sorry to (.) beh to bother you", line 3), after Leslie's "hello" at 
line 1 and a pause of 0.7 seconds at line 2. The apology is produced immediately after receiver's recognition, very similarly to (3), and it is followed by Leslie's absolution ("Oh: right", line 4). Then, Randall introduces the reason for the call (" $\uparrow$ Could you a::sk Skip if- $\mathrm{h} m \mathrm{~h}$ at- when you go: to this meeting $=$ tomorrow.h $m$ could'ee give -Geoff: Haldan's a $\downarrow$ pologies through sickness?," lines 5-8). Here, the function of the apology is to prepare the early introduction of the reason for the call, and the opening sequence compression turns out to be co-accomplished through Leslie's response at line 4.

The apology ("sorry to (.) beh to bother you", line 3) is rather formulaic, ${ }^{10}$ and the reply it receives, "oh right", at line 4, despite literally being an absolution, has also the function of validating Randall's move and aligning with his orientation to move on toward what will be the early introduction of the reason for the call (on this point, see Biassoni et al., this issue). Therefore, the sequential positioning of the apology, its content and structure, and the subsequent reply, all contribute to construct it as en passant activity.

Another formulaic parasitic apology is present in excerpt 6 ("Sorry to be $(0.2)$ bothering you agai:n", lines 6 and 7):

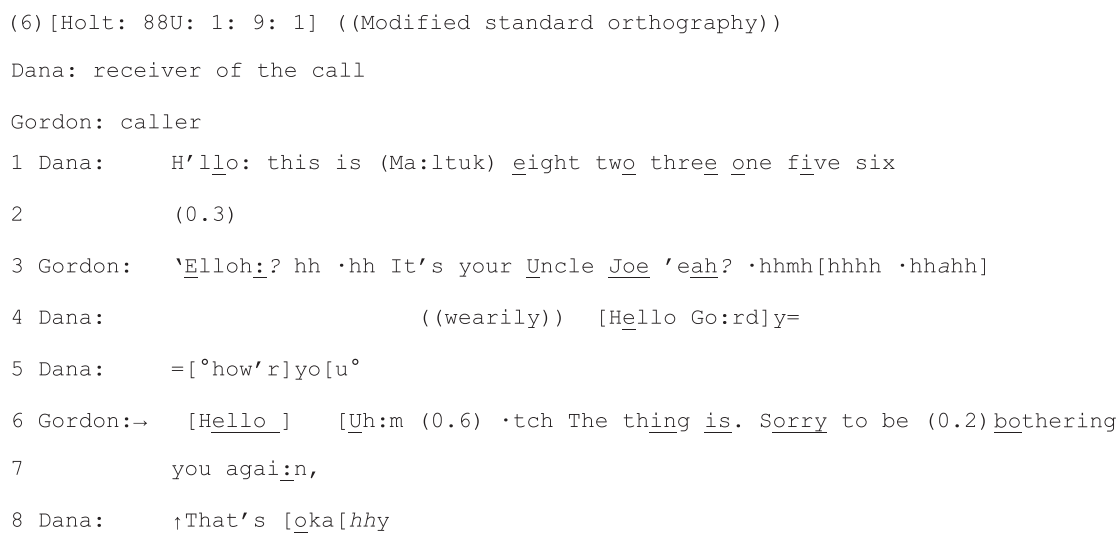

\footnotetext{
${ }^{10}$ We use the term "formulaic" according to Deutschmann (2003, p. 46). "Formulaic apologies" are a kind of "nonprototypical apologies" where "the offense is minimal" and the apologizing is a matter of routine (e.g., saying sorry for "social gaffes such as coughing, slips of the tongue, etc.") they can have "other functions in addition of repair work" (e.g., cueing a request or calling for attention). Interestingly, in extract 5 the same formulaic apology occurs at the end of the call, at line 22 , but in that position it loses the prospective function it has at line 3 , when occurring at the opening of the call.
} 


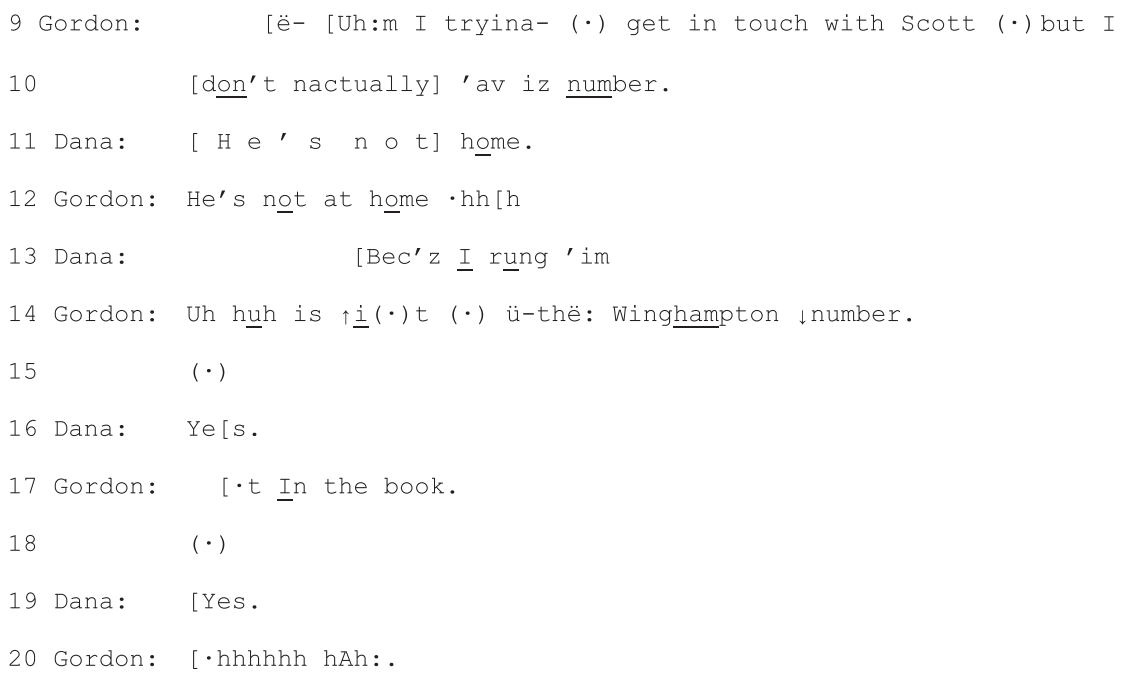

In this example the opening of the call is composed by the greetings and a recognition/identification exchange (lines 1-4), followed by the called initial "how are you" at line 5. The caller (Gordon) produces a faked form of selfidentification by jocking (“'Elloh:? hh ·hh It's your Uncle Joe 'eah?”, line 3), and the receiver (Dana) responds by a correct identification ([Hello Go:rd]y = , line 4), which is pronounced wearily. Then Dana produces a nonreciprocated "how're you" (line 5) in a lower volume, which is in overlap with Gordon's "Hello" (line 6). The reason for the call is first introduced at line 6 ("The thing is"), where the "how are you" reciprocation could occur and is interrupted by the introduction of the apology ("Sorry to be (0.2) bothering you agai:n", lines 6 and 7, followed by Dana's absolution (Robinson, 2004) " $\uparrow$ That's okahhy", at line 8. After Dana's reply to the apology, Gordon proceeds with the fully introduction of the reason for the call, that is, to ask Dana Scott's telephone number ("Uh:m I tryina- (.) get in touch with Scott", line 9). In this case the effect of urgency connected to the apology's production, besides being conveyed by its occurring within the opening sequence, is even highlighted by its placement between the first (interrupted) introduction of the reason for the call ("The thing is", line 6) and its subsequent fully formulation at line 9 ("Uh:m I tryina- (.) get in touch with Scott"), followed by a justification for the request ("I don't actually 'av iz number", line 9 and 10).

In both excerpts 5 and 6 the apology is responded to by an absolution, so that the compression of the opening phase and the early introduction of the reason for the call, to which the apology is subsidiary, turn out to be the product of an embedded apologetic exchange, collaboratively accomplished by the two parties.

Conversely, in excerpts 7 and 8 the caller goes straight on to introduce the reason for the call rather unilaterally. 


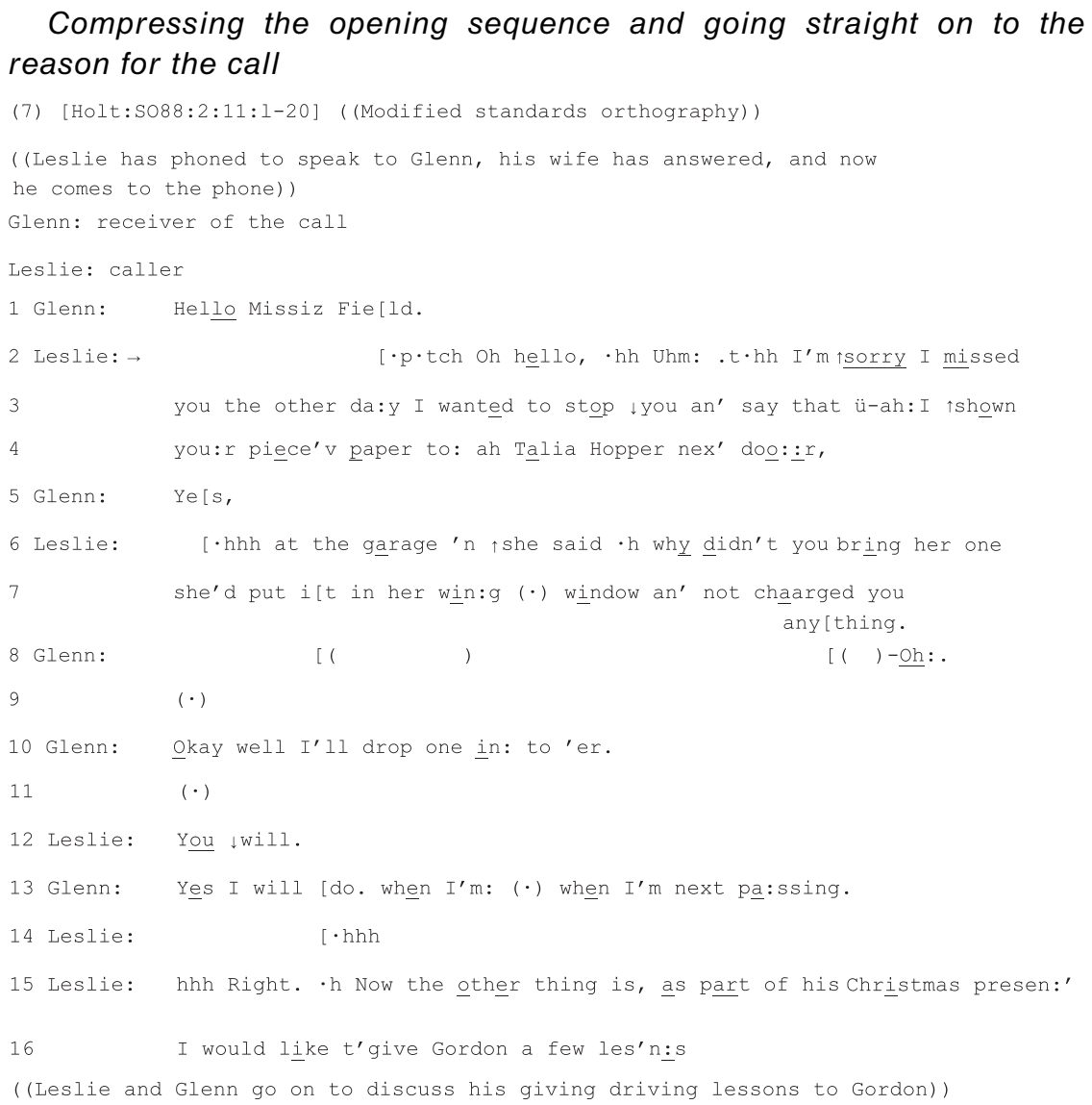

In excerpt 7 after the "hello" reciprocation and some hesitations, the caller produces an apology followed by its apologizable ("I'm $\uparrow$ sorry I missed you the other da:y", lines 2 and 3) that, differently from excerpts $\overline{5,6}$, and 8 below, is a distal contact problem. The apology is produced at the first available conversational slot after the expected response greeting so to create the same effect of urgency we found in the previous excerpts and, similarly to excerpts 5 and 6 , there is no resuming of the activity of opening the call. Indeed, after the apology Leslie introduces the first reason for the call (first because she then proceeds with a second one, at line 15), definitely going beyond the opening phase. Here, the apology is a part of a multiunit turn in which the sorry component and the mention of the apologizable (i.e., a missing contact in the past) are fully integrated into the presentation of the reason for the call. The apology's position within a more complex turn, while reinforcing its prospective 
function, ${ }^{11}$ in this case the transition to the introduction of the reason of the call, an activity to which the apology is subsidiary, also determines the absence of a conversational slot for a response to the apology, hence its irrelevance. Indeed, the interlocutor doesn't reply to the apology; Glenn's following prospective acknowledgment ("Yes", line 5) and the "Oh:" at line 8 reveal that he is orienting to Leslie's storytelling and to its informative value rather than to the apology.

In (8), the apology serves the same function of compressing the opening phase of the call:

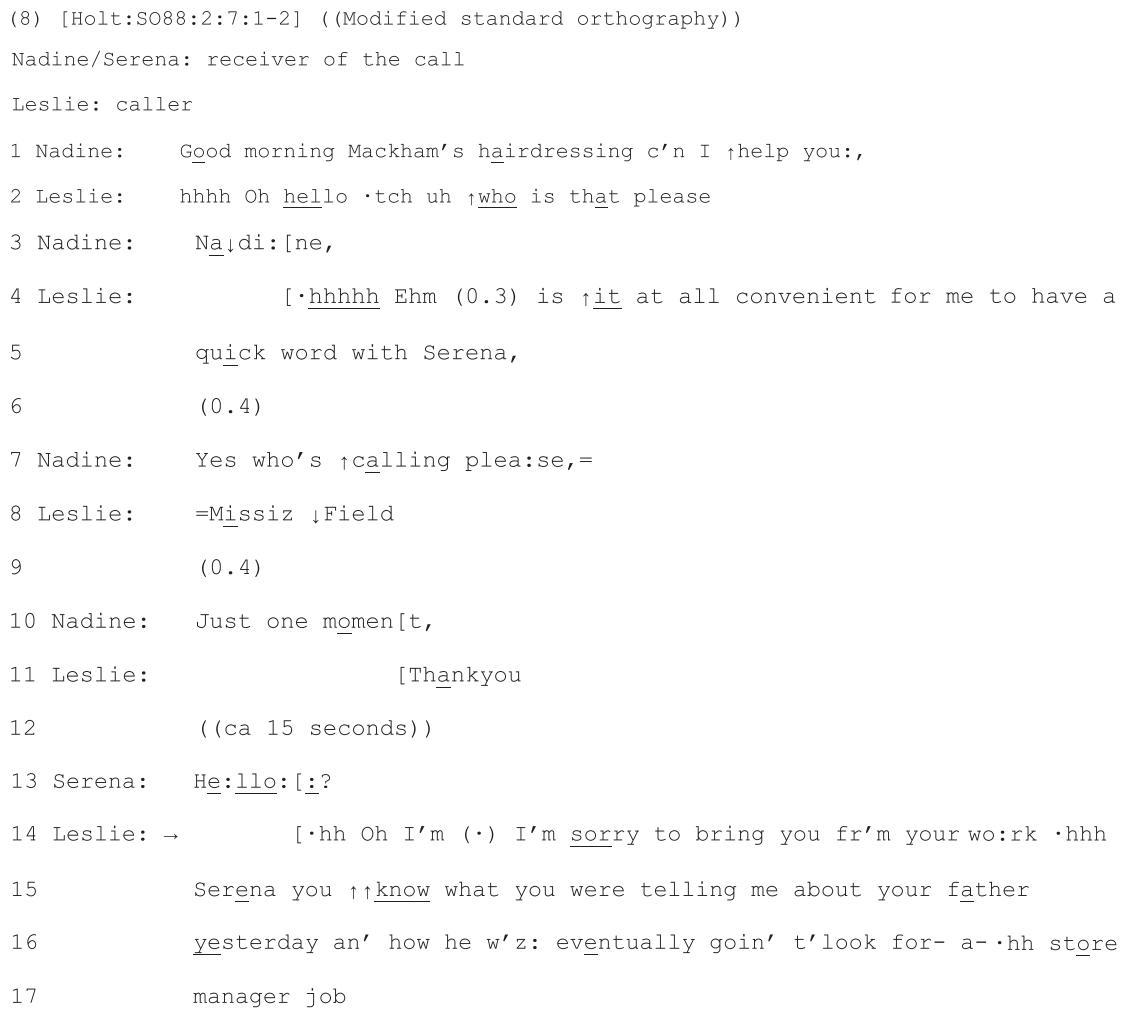

${ }^{11}$ Becasue of its prospective function, this type of apology is similar to Robinson's (2004) prefatory and subordinate (to primary action) apologies. Differently from Robinsons', the prospective function of these apologies is not to prepare a dispreferred second pair part but to introduce variations in the structure of the ongoing activity. 


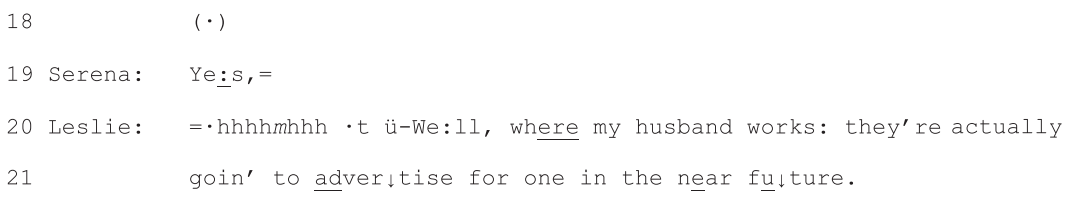

In this example Leslie calls at Serena's workplace to speak with her. Nadine answers the phone and, after a recognition sequence (lines 2 and 3 and 7 and 8) and Leslie's request to speak to Serena (lines 4 and 5), she calls Serena who comes to the phone after a lapse of 15 seconds. At line 14, immediately after getting in contact with Serena, Leslie apologizes for disturbing her at work ("I'm sorry to bring you fr'm your wo:rk").

The apology comes with the apologizable "to bring you fr'm your wo:rk", and occurs in the first part of Leslie's turn and replaces the "hello" reciprocation. Similarly to excerpt 4 , the apologizable here is a local problem, the fact of calling Serena at work, whose problematic character probably emerged because of the time that Serena took to come to the phone and Leslie's consequent waiting. As in (7), the apology doesn't suspend the main activity but definitely closes it. Indeed, there is no resuming of the opening phase, but its compression and closure are realized on behalf of a sudden introduction of the reason for the call (lines 15-17 and 20-21). No accounts follow the apology, and the transition to the subsequent phase is announced and performed through the address term "Serena" that projects the relevance of what will be said and announces the transition from the secondary component of the turn, the apology, to the core component, the reason for the call (Drew \& Chilton, 2000, p. 148).

As in the previous example, despite the in-breath at the end of line 14, after the word "wo:rk", which could have been an opportunity to take the turn, Serena doesn't reply to the apology. ${ }^{12}$ Hence, even in this case, both the interlocutors contribute to construct the apology as an en passant activity, limiting its sequential implications. As in excerpt 7, the formulation of the apology is designed in the service of the early introduction of the reason for the call and their occurring within the same multi-unit turn contributes to communicate a sense of urgency.

Beside the lack of responses, two other features differentiate (7) and (8) from the previous (5) and (6); the apology's occurring within a "second opening," second in the sense that the caller already had a previous contact with another person than the sought recipient, and the callers' promoting a "you oriented" reason for the call. Indeed, in both (7) and (8) the reason for the call is shaped as an intervention of the caller on recipient's behalf (the promotion of Leslie's work

\footnotetext{
${ }^{12}$ For an analysis of this extract, and particularly of this point, see Schegloff 2005: 467.
} 
in excerpt 7 and some relevant information about a possible job for Serena's father in excerpt 8). In particular, the latter feature, by mitigating the potential intrusiveness of the call, may contribute to legitimate the unilaterally accomplishment of the opening sequence compression on behalf of the early introduction of the reason for the call.

\section{DISCUSSION}

We identified a type of apology we termed parasitic apologies because they are subsidiary activities to the main business of opening the call (excerpts 3 and 4) or introducing the reason for the call (excerpts 5-8). The effect of remaining these apologies parasitic to the main activity is obtained through two main features: their occurring in the opening sequence, delaying or replacing the execution of one of its standard components, and their being a rather compressed sequence, as they introduce the apologizable and mostly receive rather unelaborated replies or no reply at all. Furthermore, in our corpus the apologizables are always problems in getting in touch. They can arise out of past actions or emerge within the ongoing interaction and are also linked to actions such as calling, disturbing, or making the interlocutor wait on the phone.

The analysis has shown that parasitic apologies impact on the structure of the opening sequence in one of two ways: they may temporarily suspend it and delay resumption (excerpts 3 and 4) or may lead to its closure on behalf of an immediate transition to the reason for the call phase (excerpts 5-8). The two different alterations of the opening sequence-that is, suspending versus compressing and closing the current phase-are associated with the identity of the apologizer. The apologies that suspend the opening stage and are later resumed (excerpts 3 and 4 ) are accomplished by the receiver of the call, whereas all the apologies leading to the opening sequence compression and to the early introduction of the reason for the call (excerpts 5-8) are produced by the caller. The correlation is not surprising if we consider that the opening phase of a call is rather strict regarding the relation between the caller/call receiver role and the type of contributions they can produce, the canonical structure foresees that it is up to the caller to introduce the reason for the call. Nonetheless, even call receivers can introduce topics during this phase. They can do that through the accounts they introduce after the apologies (see excerpts 3 and 4), but, differently from the topics introduced as a reason for the call, those topics remain subsidiary to the apology and are not developed further.

The category of parasitic apologies that entails the early introduction of the reason for the call (excerpts 5-8) was further analyzed in two subcategories according to the presence versus the absence of a response to the apology. We distinguished two main formats: [apology component] + [apologizable] + 
[response to the apology] + [reason for the call] and [apology component] + [apologizable] + [reason for the call]. It is noteworthy that in cases where the caller doesn't receive any response to the apology and directly introduces the reason for the call (excerpts 7 and 8), the apologizable is something for the benefit of the called party. Conversely, when the apology receives a response (excerpts 5 and 6) the reason for the call is a request to the advantage of the caller. As we have shown, when the caller proposes the compression of the opening sequence to early introducing his or her needs or requests, the proposal tends to be subject to the apologizee acceptation, even absolution, and the apologetic exchange is thus expanded and collaboratively produced through a response to the apology.

The "compressing parasitic" apologies differ from the "suspending parasitic" apologies also in the absence of the account component. Indeed, after the apology component ("I'm $\uparrow$ sorry") and the apologizable, in all the examples of compression of the opening sequence, the apologizer never produces an account but directly proceeds to introduce the reason for the call. It is noteworthy that the lack of account contributes to reinforce the prospective function of these apologies at the expense of their apologetic function. Indeed, in all these cases the remedial action is briefly outlined to legitimate the compression of the standard opening phase on behalf of an early introduction of the reason for the call.

The two outcomes of parasitic apologies we have identified-suspending or closing the current conversational phase-have in common a special relationship with the urgent need to repair potential relational troubles, even before they emerge in the interaction as complaints or actual troubles. The effect of urgency is obtained through the apologies' intrusion in call openings and through the alteration of the opening sequences that this intrusion entails.

Producing an apology in this particular sequential location is evidence that social actors treat the opening of a contact as a suitable site to repair potential relational problems, mainly emerging from distal or local contact troubles. For the interlocutors, parasitic apologies are effective devices to display the relevance that they ascribe to remedial work and, more generally, to the ritual dimension of interaction.

\section{ACKNOWLEDGMENTS}

We thank Francesca Di Presa for her contribution to the initial project that led to this article.

\section{FUNDING}

Biagio Ursi is grateful to the ASLAN LABEX (ANR-10-LABX-0081) of Université de Lyon for financial support within the program "Investissements 
d'Avenir" (ANR-11-IDEX-0007) of the French government operated by the National Research Agency (ANR).

\section{REFERENCES}

Deutschmann, M. (2003). Apologising in British English. Umeå, Sweden: Umeå University.

Drew, P., \& Chilton, K. (2000). Calling just to keep in touch: regular and habitualised telephone calls as an environment for small talk. In J. Coupland (Ed.), Small talk (pp. 137-162). New York, NY: Longman.

Heritage, J. (1984). A change-of-state token and aspects of its sequential placement. In J. M. Atkinson \& J. Heritage (Eds.), Structures of social action (pp. 299-345). Cambridge: Cambridge University Press.

Robinson, J. D. (2004). The sequential organization of "explicit" apologies in naturally occurring English. Research on Language and Social Interaction, 37, 291-330.

Schegloff, E. A. (1986). The routine as achievement. Human Studies, 9, 111-151.

Schegloff, E. A. (2005). On complainability. Social Problems, 52, 449-476.

Schegloff, E. A. (2007). Sequence organization in interaction. A primer in conversation analysis (Vol. I). Cambridge, UK: Cambridge University Press. 